\title{
A PRODUÇÃO LITERÁRIA DE JORGE MIGUEL MARINHO NO HORIZONTE DOS ANOS 80
}

\section{THE LITERARY PRODUCTION OF JORGE MIGUEL MARINHO IN THE EIGHTIES}

Rafaela Stopa ${ }^{1}$

Resumo: Tendo em vista que a produção literária de quase cinco décadas do escritor Jorge Miguel Marinho (1947-2019) conta com expressiva publicação de obras para o leitor jovem, este artigo tem por objetivo abordar os livros juvenis em prosa do escritor publicados na década de 1980, quando inicia sua carreira de escritor, buscando compreender sua inserção no segmento.

\begin{abstract}
Considering that the nearly five decades literary production of Jorge Miguel Marinho (1947-2019) has had a significant publication for young readers, this article aims to approach the author's juvenile books in prose, published in the decade of 1980 , when he began his career as a writer, in order to understand his integration into the field.
\end{abstract}

Palavras-chave: Jorge Miguel Marinho; Literatura juvenil; Narrativas.

Keywords: Jorge Miguel Marinho; Youth literature; Narratives.

\section{Introdução}

Jorge Miguel Marinho (1947-2019) é autor consagrado no campo da produção literária para a criança e o jovem. No ano de 2017, foi agraciado com o hors concours pela Fundação Nacional do Livro Infantil e Juvenil - FNLIJ. Sua produção de mais de 30 livros é variada em gênero e público, com foco no segmento infantojuvenil. Com o primeiro livro voltado ao leitor jovem publicado na década de 80 , suaobra ajuda a entender as transformações pelas quais passaram e ainda passam a literatura infantil e juvenil nacional, colabora para esboçar o perfil de livro apreciado por instituições literárias responsáveispor premiações, assim como,os componentes de sua criação podem ajudar a perceber características comuns ou não a esse segmento.Tendo em vista uma produção de quase cinco décadas, este artigo aborda os livros juvenis em prosa do escritor publicados na década de 1980, inseridos em seu contexto histórico, buscando compreender sua entrada no segmento.

Em 1981, o autor publicou, por uma pequena editora, a coletânea de poemas O talho. Em 1984, veio a público o livro Escarcéu dos corpos: sete histórias de carne e osso, pela editora Brasiliense, na coleção Cantadas literárias, que era voltada ao público universitário e alcançou boa recepção

1 É doutora e mestre em Letras pela UNESP/Campus Assis. Especialista em Estudos Linguísticos e Literários pela Faculdade Estadual de Filosofia, Ciências e Letras de Jacarezinho. Graduada em Letras/ Literatura pela mesma instituição. É professora adjunta do Centro de Letras, Comunicação e Artes da UENP/Campus Jacarezinho e atualmente está na Direção do CLCA/CJ. 
da crítica. Seu primeiro livro de contos foi lançado em uma coleção cujos temas e procedimentos formais atendiam às demandas de jovens do momento de abertura política, quando a relação entre produção, mercado e consumo já demarcava sua força. Nesse ínterim, enquanto os escritores tinham de se acomodar aos novos moldes de profissionalização, o leitor, segundo Pellegrini, foi aprendendo "a se inserir num universo de leitura em que as coordenadas de escolha e fruição não são estabelecidas apenas 'por si', mas por todo um jogo mercantil - cujas regras não conhece - e por um processo de difusão bem distante das letras" (1999, p. 156).

Em meio esse cenário, depois da publicação de Escarcéu dos corpos, Marinho dedicou-se durante mais de uma década, exclusivamente, à literatura juvenil, de tal maneira que nos anos 80 houve cinco títulos nesse segmento. O foco recaiu sobre um público menos autônomo que o universitário, mas nem por isso menos exigente. Conforme o autor, em entrevista a Jorge Vasconcelos:

\begin{abstract}
Alguém já disse que um bom texto juvenil é um texto que os jovens gostam de ler e, não por acaso, os menos jovens também. De qualquer forma, ao menos para mim, há um ganho inestimável nesse tipo de criação: na medida em que escrever para jovens é realização um pouco mais condicionada pela presença de um leitor específico, há mais empenho do escritor em fazer da expressividade literária fato comum, comunicação. Isto evidentemente sem abrir mão da singularidade desse tipo específico de criação (MARINHO, 1994).
\end{abstract}

Em 1986, com a publicação de $A$ menina que sonhava e sonhou, novela disponível na coleção Terceiras Histórias, da FTD, Marinho - que era o único estreante no segmento - viu seu nome junto ao de autores como Sylvia Orthof, Antonio Hohlfeldt, Pedro Bandeira e Marco Túlio Costa. Possivelmente, a boa recepção de Escarcéu dos corpos lhe abriu as portas das editoras, em um período de prosperidade do segmento, que se inicia, como apontam Lajolo e Zilberman (1985), a partir dos anos 60, quando se multiplicam as instituições e programas voltados ao debate sobre a leitura e a literatura infantil, com o apoio financeiro do Estado para publicações. Dessa feita, "muitos autores, inclusive os consagrados, não desprezaram a oportunidade de inserir-se nesse promissor mercado de livros, o que trouxe para as letras infantis o prestígio de figuras como Mario Quintana, Cecília Meireles, Vinícius de Morais e Clarice Lispector" (1985, p. 124).

Ana Maria Machado, ao traçar um breve panorama do desenvolvimento dessa literatura no Brasil, resgata o contexto da ditadura militar para mostrar que houve um salto qualitativo quando bons autores passaram a usar a literatura infantil e juvenil para se expressar livremente:

Como toda e qualquer literatura, sem adjetivos relacionados à faixa etária dos leitores, essa 
nossa literatura não surgia do destinatário, mas dos autores. Daí sua força. Era feita por gente que, se estava escrevendo também para crianças e jovens, não era necessariamente oriunda de áreas que trabalhassem com pedagogia ou psicologia infantil, mas que chegava à escrita naturalmente, pelo amor à leitura (MACHADO, 2007, p. 119, grifo do autor).

Nesse contexto, os livros infantis e juvenis proporcionaram atrativos para os escritores, haja vista o apelo mercadológico, mas também, a maior liberdade de criação. No período, floresce uma literatura infantil e juvenil mais contestadora, tematizando o autoritarismo, a injustiça, a miséria, a conquista da identidade, o preconceito, de modo que se assiste "submergir a velha prática de privilegiar nos livros infantis apenas situações não problemáticas" (LAJOLO; ZILBERMAN, 1985, p. 126). Entre outros, destacam-se os autores: Edy Lima, João Carlos Marinho, Wander Pirolli, Sérgio Caparelli, Mirna Pinsky, Fernanda Lopes de Almeida, Ana Maria Machado, Bartolomeu Campos de Queirós, Ruth Rocha, Lygia Bojunga e Marina Colasanti.

Com esse time, especialmente nos anos 70 , os gêneros são variados, havendo a ficção científica, o mistério policial, o surrealismo e o fantástico. Merece ênfase a tematização da miséria e do sofrimento infantil de matiz urbana, com a presença de menores abandonados em grandes centros. Enquanto esse momento mostra uma crença no potencial da literatura para mudar as estruturas sociais com o desvelamento de uma sociedade desigual e injusta, as próximas décadas apresentam uma maior sintonia com o mercado e sua pressa, reforçando os modos de produção que caracterizam a literatura infantil e juvenil desde seu início. Como pontua Marisa Lajolo, já no período de sua formação são definidos

[...] os canais que, em nosso país, agilizam a circulação e o consumo da literatura destinada a crianças: um deles é o Estado Todo Poderoso. Se não o Criador do Céu e da Terra, pelo menos o Distribuidor de Livros e Agenciador de Leitores. Outro é a Escola. E quando a Escola escapa do Estado ao qual serve e do qual é um aparelho ideológico, cai nas malhas da indústria editorial. O equilíbrio é mais do que precário; quer como instrumento do Estado, quer como instrumento do capital, a escola é entreposto compulsório do livro infantil brasileiro que quiser abandonar a poeira das estantes e chegar às mãos dos leitores (1986, p. 44).

Por mais que, temática e esteticamente, essa produção tenha acompanhado os rumos da canonizada, tendo se modificado sensivelmente, sua estreita relação com a escola pouco se alterou, tornando pertinente a retomada da fala com mais de trinta anos de Lajolo. Isso é facilmente verificável na contemporaneidade através do PNBE - Programa Nacional da Biblioteca da Escola, cuja 
suspensão em 2015 causou um desmonte de pequenas editoras, e levou muitas outras a recorrerem à diversificação de estratégias para emplacarem as vendas. Ou seja, o Estado se mantém o Todo Poderoso dessa relação. O desvincular-se de padrões utilitários não significou necessariamente um grito de independência para a produção infantil e juvenil com parca tradição de leitura. Como apontou Lajolo, para sair das estantes, o melhor caminho é o da escola.

A trajetória de Marinho, nesse contexto, é bastante representativa das singularidades da produção literária para crianças e jovens a partir da década de 80. Sua estreia no segmento ocorreu em 1986, na coleção Terceiras Histórias. No ano seguinte, seu segundo livro juvenil Dengos e carrancas de um pasto sai pela mesma coleção, que recebe a seguinte descrição no site da editora FTD: "textos e temas mais densos. Quando nossos leitores amadurecem, as histórias devem mudar com eles". Daí a ideia de "Terceiras", pois é como se o público visado já tivesse passado por outros tempos de leituras. Vale destacar, que há mais de um século, a FTD atua no Brasil com livros didáticos e paradidáticos para todas as áreas de ensino, além dos literários. No último caso, há desde clássicos da literatura nacional e estrangeira até títulos que atendem claramente a temas transversais, os quais são acompanhados de projetos de leitura e indicação de datas comemorativas.

Em consonância à fala de Lajolo, Marinho se introduz no segmento juvenil via escola, como era comum nos anos 80, mas não quer isso dizer que seus livros perpetuem as tendências utilitaristas que nessa época ainda eram comuns a algumas publicações, pelo contrário. Os dois títulos do autor inseridos na coleção apresentam linguagem poética e tratam da temática amorosa de maneira inusitada.

\section{Descobertas de si}

A menina que sonhava e sonhou traz a história de Mazda, descrita como "sonhadora, sonhadeira, sonhadenta" (MARINHO, 1986, p. 4). Fica traçado, desde o início, um perfil de comportamento comum aos jovens, mas criticado pelos adultos: o viver com a cabeça nas nuvens. A menina tanto sonha acordada que é difícil precisar a diferença entre devaneio e realidade, o que, é claro, causa preocupação em seus familiares. Os pensamentos nada têm a ver com artigos de consumo, namoros ou desejos por outra vida; seus sonhos são com deuses barbudos, bailarinas, cavalos em carruagens, que acabam interferindo em sua vida, pois se atrasa para a escola, derruba seu café e perde o ônibus.

Em meio aos devaneios de Mazda aparecem algumas pinceladas de sua relação com a família, tema recorrente em livros juvenis: "Mazda acha que gosta da família. Tem dia que o carinho é maior que o jeito de gostar. Quem sabe, pegar na mão ou deitar a cabeça nas pernas de um deles e contar. Contar o quê? Um sonho bem bonito, afinal de contas ela só sabe sonhar" (MARINHO, 1986, p. 14). Mesmo que de forma jocosa, o padrão de comportamento é tão reforçado na narrativa que poderia se tornar artificial, parecendo servir tão somente à conclusão que se queria entregar ao leitor, não fosse o 
fato de a solução do conflito ser independente de qualquer intervenção de adultos, que, aliás, seguem na narrativa sem compreender a menina.

$\mathrm{O}$ amadurecimento de Mazda se delineia ainda através dos tempos verbais escolhidos pelo narrador onisciente. De início, o pretérito imperfeito reforça a recorrência dos sonhos da menina. Num segundo momento, quando ela reflete sobre sua relação com a família, a ação passa para o presente, configurando uma pausa em seus devaneios. Em seguida, quando a protagonista se olha no espelho e percebe as estrelas que brilhavam pelo seu corpo - uma bela metáfora do início da puberdade, - o narrador usa o passado simples, pois a incompreensão dos adultos, nessa fase, parecia eterna aos olhos da garota. As dificuldades são amenizadas com a descoberta do primeiro amor na escola, quando é retomado o pretérito imperfeito, já que a partir de então, nada é definitivo.

Trata-se de narrativa curta, são apenas 24 páginas, com ilustrações de Alcy que colorem as fantasias de Mazda. Há dois desenhos que mostram a protagonista nua, ora sob os olhos de uma mãe espantada com sua magreza ora na descoberta que faz de si em frente ao espelho, colaborando na construção do inusitado no texto. O leitor acompanha, longe de quaisquer didatismos, a difícil e delicada relação do adolescente com o mundo adulto para o qual está caminhando.

É também lúdico Dengos e carrancas de um pasto (1987), que da mesma forma que $A$ menina que sonhava e sonhou, trata da descoberta de si, e consequentemente, de outras descobertas. Porém, como aludido no título, os personagens são bois e vacas que, à semelhança de humanos, têm crises de identidade, problemas de relacionamento e estão insatisfeitos com o trabalho, de tal maneira que perpassam a narrativa temas como a alienação, o preconceito, a estratificação social, entre outros, sob o pano de fundo das relações amorosas.

Tais temáticas se desenvolvem numa linguagem poética, mas vazada em muitas frases feitas, como em "Boi sonha tanto que chega a babar" (1987, p. 7); “- Opinião, minha filha! Nada de baixar a cabeça e ser vaquinha de presépio" (1987, p. 9); “- Ora, garoto! Isso é conversa pra boi dormir!” (1987, p. 12); “- Vamos cuidar da vida, minha gente, porque dessa vez a vaca foi pro brejo mesmo" (1987, p. 13). Apesar do excesso, elas harmonizam com a história, que é inusitada e divertida, como as ilustrações de Helena Alexandrino, que reforçam o tom humorístico ao revelarem bois e vacas com traços humanizados e infantilizados.

Ao que parece, linguagem verbal e visual faziam um contrapeso aos temas mais profundos das entrelinhas, suavizando-os. Por isso, surpreende que, na reelaboração de 2007, pela editora Peirópolis, além da mudança de título para $O$ boi cor-de-rosa, as ilustrações de Taisa Borges apresentem cores fortes e vibrantes, sem qualquer matiz humorístico, ao contrário: ao representar os animais sem traços humanizados, os sentimentos abordados no texto se insinuam mais especificamente nas cores e formas.

Essa nova edição é, sem dúvida, mais agradável ao toque e ao olhar, o que se confirma pelo fato de ter sido selecionada para integrar o Catálogo de Bolonha 2008 - FNLIJ - Categoria ficção 
para crianças, mas tornou ainda mais dúbio o endereçamento do livro, já que as ilustrações restaram tão metafóricas quanto o texto. As causas que levaram à alteração do título podem ser variadas, mas o que se esclarece é que a nova edição tem uma apresentação textual e visual que demarca bem menos o público, haja vista o processo de "desinfantilização" pelo qual passou.

O livro Dengos e carrancas de um pasto detém-se nas dificuldades de ser touro e por filhos no mundo sem que seja possível cuidar deles, além do fato de não haver liberdade para escolher seus próprios amores. Abdias, tão cansado que estava dessa vida, começou a praticar meditação. "Um dia meditou mais de cinco horas seguidas e acabou chegando na fazenda vizinha de tanto levitar. A vaca Genoveva ficou gagá pro resto da vida quando viu Abdias de pernas abertas voando no céu" (MARINHO, 1987, p. 10). O acontecimento prodigioso é narrado com dados realistas, de modo que o insólito torna ainda mais metafórico o livro: o voar pelo céu simboliza o desejo da liberdade, de conhecer o que há após a cerca.

Abdias morre e em seu lugar chega o touro Boizebu Bezerro de Meneses, o Zé, que era sonâmbulo, cantava ópera e certo dia amanheceu com castanholas no lugar das orelhas. "O Zé teve de usar um gorrinho verde por um tempão e felizmente as orelhas voltaram ao normal" (MARINHO, 1987, p. 16). O medo da recusa ao diferente fica explícito na atitude de Zé ao esconder suas castanholas; e essa não aceitação do que vai contra os padrões socialmente estabelecidos se acentua com o nascimento de Capistrano, o Luar, que fica cor de rosa de acordo com suas emoções.

A vida de Luar é agitada e cheia de paixões: a primeira é pela vaca Graúna com quem achou que ficaria para sempre, mas isso não fora possível, pois teve de namorar outras. "Luar cruzou com todas elas pensando no pelo de Graúna e todos os bezerros dessas crias nasceram pretos no pelo e pretos no olhar" (MARINHO, 1987, p. 34). Cansado, Luar resolve fugir, mas é surpreendido por uma Graúna que se preocupava apenas com os litros de leite para produzir. Fora engolida pelo sistema.

Depois veio Juanita, uma vaca muito sensível que logo faleceu, o que fez Luar romper a cerca e buscar outra vida. Pelo caminho se apaixonou por uma flor amarela - arrogante como a rosa do Pequeno Príncipe, - que não sabia compartilhar seu amor, levando o touro a desistir. Apaixonou-se então por uma borboleta, que lhe correspondera, e ambos precisaram aprender a se amar em corpos fisicamente distintos. Porém, sua amada vai embora; foi quando "Luar descobriu que amor tinha bastante desencontro e que na vida era difícil demais fazer amor num mesmo lugar" (MARINHO, 1987, p. 45). Mais do que representar as relações entre homens e mulheres de forma geral, estão aí simbolizadas as dúvidas, perspectivas e aspirações de jovens, os destinatários do livro, sobre os relacionamentos.

Fica ratificado, então, que Marinho se insere no segmento juvenil por meio de uma editora com fins claramente pedagógicos sem que isso comprometa o rendimento estético e a criatividade de seus textos. Naturalmente, como são livros para jovens, não se perde de vista a expectativa do aprendizado e do crescimento para a vida, mas sem moralismos ou explicitações de comportamentos. 
Como pontuam Lajolo e Zilberman,

se aparentemente desapareceu desses livros infantis o compromisso com a história oficial, com os heróis pátrios e com os conteúdos escolares mais ortodoxos, um exame mais atento da produção infantil contemporânea revela a permanência da preocupação educativa, comprometida agora com outros valores, menos tradicionais e - acredita-se - libertadores (1985, p. 161).

Libertador. Esse é um adjetivo que harmoniza com os textos de Marinho, seja pela perspectiva de se tratarem de narrativas desvencilhadas de didatismos, seja pelo fato de seus personagens buscarem, ao mesmo tempo, seu lugar no mundo e sua liberdade. Uma liberdade que pode ser transformadora não somente para si, mas também para o outro.

\section{Descobertas do viver e do amor}

Transformação. É esse o caminho que segue mais um livro do autor publicado em 1987, Um amor de maria-mole, pela editora mineira Lê, na coleção Momentos, dirigida a jovens. Na quarta capa, informa-se sobre os textos que a compõem são "curtos e vibrantes, retratando questionamentos, incertezas, anseios e emoções" (1987).

Novamente, quem protagoniza a história é uma menina, e a descoberta amorosa é tema de destaque. Dessa vez, a narrativa é em primeira pessoa, o que confere ao texto um toque mais confessional e de proximidade com o leitor, que muito possivelmente vai se identificar com a linguagem e a visão de mundo de Sandra. Como uma típica adolescente, tem problemas com sua própria imagem e se sente deslocada entre os amigos da escola e sua família. Suas dificuldades de estar no mundo só começam a ser resolvidas quando conhece Gilberto e ele lhe oferece uma maria-mole.

O sabor açucarado e a textura macia da maria-mole contrastam com a vida dura de Sandra, abandonada pelo pai desde sua concepção, e pela mãe, que trabalha como viajante. $\mathrm{O}$ doce simboliza a primeira oportunidade que Sandra tem de se abrir para algo ou alguém. Isso porque ao aceitar a maria-mole aceitou também Gilberto: é quase uma epifania. “-É a primeira vez que eu adoro. Hoje eu adorei” (MARINHO, 1987, p. 23). A sobremesa lhe abriu as portas para entender que a vida não era só amargura; com Gilberto percebeu a riqueza das diferenças e que as oportunidades estão na forma de olhar. Tudo muito poeticamente:

Sempre comendo e oferecendo maria-mole pras pessoas, nós conversamos com navegadores 
antigos, fadas que moravam em quitinetes e até mágicos que estavam preparando a mudança da terra, sem cartola, sem coelho e sem cortar loiras bonitas com lâminas num caixão. Gilberto fez sinal que eles já tinham provado maria-mole, mas eu não entendi (MARINHO, 1987, p. 26).

Os jovens trocam seu primeiro beijo, mas o garoto vai embora de São Paulo com os pais, deixando em Sandra a vontade de compartilhar com outras pessoas os segredos da maria-mole. Apesar de muito procurar, a jovem não encontra uma explicação racional para as sensações provocadas pelo doce, tal qual a impossibilidade de se entender logicamente o amor. "Quando a gente come mariamole, a gente sente uma delícia na pele e lá dentro. Daí começa a se sentir” (MARINHO, 1987, p. 33). Sandra vira doceira da vida e é a partir dessa escolha que o insólito surge na narrativa.

Ao comer o doce ofertado pela menina, as pessoas apresentam reações estranhas que parecem, como no caso de Sandra, serem reveladoras e motores de mudanças. Teve bolha que estourou mariamole, bola de maria-mole surgindo embaixo de um colchão e uma cozinheira que botava feijão para cozinhar, mas na hora de servir só tinha o doce. O realismo maravilhoso torna essa história de mariamole e amor ainda mais inusitada e poética.

Vale destacar, ainda, o sutil diálogo que se estabelece com A paixão segundo $G$. $H$., de Clarice Lispector, tanto pela perspectiva de busca que entremeia a trajetória da protagonista quanto pelas epifanias. Inicialmente, Sandra esclarece que apesar de se sentir deslocada nunca parava de procurar, e após se descobrir ao comer maria-mole, quer que outras pessoas possam se autoconhecer, ou seja, espera que todos encontrem sua própria revelação. Ao sair distribuindo seus doces, refletiu: “os outros podem até me chamar de louca, nem me interessa. Sabe por quê? Este jeito gostoso da maria-mole foi tudo o que esperei de uma emoção" (MARINHO, 1987, p. 33). Semelhante à G. H. e sua alegria em dar as mãos a alguém.

Também é de 1987 A visitação do amor, que saiu pela editora Contexto, na coleção "Contexto jovem", que se propunha a lançar "pequenos romances, com histórias atraentes, bem escritas e selecionadas com a colaboração de alguns jovens" (1987, 4ª página). Apesar de a história em questão ser realmente atraente, o projeto gráfico-editorial é simples, sem ilustrações, com letras e espaçamentos pequenos e uma capa pouco cativante, de modo que não combina com o texto verbal. E por mais que o ditado popular previna para que não se julgue um livro pela capa, os aspectos externos de um livro influenciam em seu julgamento, pois não raro indicam uma possível percepção da obra.

Entretanto, pela delicadeza com que a história é contada, o diálogo produtivo que mantém com clássicos e seu caráter alegórico, a despeito do projeto gráfico-editorial pouco cuidadoso, o livro recebeu o prêmio “O Melhor para a Criança” FNLIJ 1988 (Jovem) e o Selo Altamente Recomendável FNLIJ 1988. Em seu primeiro romance juvenil, Marinho obtivera reconhecimento de uma instituição 
importante do segmento, que nesse ínterim, premiava há pouco mais de uma década.

A narrativa, como sugerido no subtítulo, traz a música como metáfora da vida, e apresenta uma releitura inusitada de personagens e eventos de contos de fadas. Trata-se de livro delicado e envolvente que traz a história de Antônio, um menino cujo destino extraordinário é explicitado em seu batizado, quando Dona Fada profetiza que ele não poderia viver sem música; tal circunstância ocorre em sua adolescência, quando qualquer som que remeta à musicalidade é banido do Pequeno Reino e ele, e consequentemente, toda cidade, tornam-se sonolentos.

A situação é bastante simbólica, pois é motivado por essa realidade opressora que o jovem sonolento vai precisar amadurecer para lutar ao lado dos amigos que compartilham de sua necessidade de música para viver - Nícolas, um anão encantado tocador de violino, e Tereza, um anjo caído do céu, - e salvar o Pequeno Reino. Nesse romance, a maldade não está em uma bruxa ou outra vilã, e sim na falta de bom senso da própria população local, que assustada com os poderes da música, opta não por entendê-la ou apreciá-la, mas por bani-la.

Para Ceccantini, "de uma perspectiva mais genérica, a narrativa [A visitação do amor] pode ser vista como uma ampla categoria de caráter social, constituindo um contundente libelo contra toda e qualquer forma de autoritarismo (individual e social), em relação ao qual é preciso se insurgir" (2000, p. 179). E ainda, para o pesquisador, restringindo o enfoque, seria possível perceber na alegoria um fato da história recente do país - a ditadura. É Tereza quem parece ter consciência do que ocorreu na cidade:

E foi ouvindo e olhando atentamente as coisas que Tereza descobriu que havia uma pátria distraída no Pequeno Reino e teve uma enorme vontade de ter nascido ali. Sentiu tanto a dormência da cidade que lamentou não ter trazido uma trombeta para clamar pelo Pequeno Reino como se clamasse por antigos arqueiros que protegiam os palácios reais (MARINHO, 1987, p. 57).

Se o diálogo com o conto $A$ bela Adormecida, na versão dos irmãos Grimm, é evidente, o romance juvenil em questão ao não trazer apenas o jovem como responsável pelas mudanças no Pequeno Reino, e sim todos os prejudicados, mostra ao leitor mais do que apenas uma fase do amadurecimento, como no caso do conto original, pois reforça simbolicamente o valor da união em tempos ligeiros.

Outros contos de fadas estão presentes no livro, como nos capítulos cujos títulos remetem a personagens também clássicos, como “Diga, espelho meu!”(MARINHO, 1987,p. 16), "Uma Cinderela presa no céu” (MARINHO, 1987, p. 19), "A brancura de Antônio e os sete tons" (MARINHO, 1987, p. 20), dentre outros que confirmam a atmosfera maravilhosa da narrativa, e a intertextualidade. E 
enquanto a história de Antônio retoma a de Bela Adormecida, a de seu primeiro amor, Tereza, guarda proximidade com a de Cinderela, pois ela é um anjo que limpa a poeira cósmica de estrelas, e sonha com outra vida. Assim, esse romance juvenil, criativamente, renova enredo e personagens.

\section{Fechando com chave de ouro}

Seu último livro publicado na década de 80 foi $\mathrm{Na}$ curva das emoções: histórias de pequenas e grandes descobertas, pela editora Melhoramentos. São sete contos cuja tônica está esclarecida na epígrafe que traz texto de Clarice Lispector: "liberdade é pouco. O que desejo ainda não tem nome" junto à seguinte explicação do autor: "Por isso estas histórias queriam ser contadas por borboletas saindo da crisálida, qualquer coisa como um livro escrito com o pólen das primeiras transgressões" (MARINHO, 1989, p. 9).

Essa é justamente a sensação que se tem ao ler os contos: parece que foram escritos por jovens ávidos de busca. A imagem da borboleta permeia todo o livro e até mesmo alguns títulos de contos. A justificativa para a presença do inseto está no texto complementar à epígrafe: trata-se de uma metáfora do jovem que rompe sua casca para alçar voo pelo mundo. Transformação é o mote dos contos cujos temas são variados e vão desde a descoberta do passado de uma avó anarquista a casos mais espinhosos, como um aborto.

A intertextualidade com textos de Lispector na construção de personagens e na elaboração textual da história de uma jovem que vê sua vida transformada após a leitura de A paixão segundo G. $H$. enriquece os contos e deixa demarcada a paixão pela escritora que se traduziria, anos mais tarde, no livro Lis no peito. O poeta Drummond de Andrade marca presença: seu poema "Quadrilha" é parodiado no conto "As borboletas copulam no voo". Mesmo frente a todas essas singularidades, o destaque do livro fica por conta da abordagem explícita, mas poética, da sexualidade.

"O umbigo de Isaura" traz a história de uma garota com extrema dificuldade de lidar com suas transformações físicas e emocionais, que encontrou no gesto de esfolar o umbigo um modo de distrair suas frustrações. Essa necessidade de se autodescobrir e sua paixão pela palavra coisa, - pois "dentro dela cabia tudo o que ela não alcançava com os olhos e de todas as sonoridades era o som mais real" (MARINHO, 1989, p. 11), - vão dando a tônica do diálogo com Lispector, que culmina no encontro revelador que Isaura tem com um cego, lembrando o conto "Amor", da escritora modernista.

Desse encontro, surge uma amizade regada à leitura de poesias e a percepção de Isaura de que o centro do universo não estava em si, mas no compartilhar seus desejos e anseios, levando-a à descoberta de sua sexualidade: 
Estava quase para esfolar o umbigo quando se viu tocando os olhos de um cego e beijando a boca de um homem no mais completo estado de avidez. Ficou cheia de saliva. Havia uma umidade quente na barriga, nos seios, na planta dos pés. Não sabia bem o que estava acontecendo, era uma vontade diferente, uma fome de não comer depressa demais. Isaura sabia e não sabia, mas achou melhor ficar apenas sentindo que dentro do seu oco ia pulsando uma coisa de mulher (MARINHO, 1989, p. 23).

O primeiro e único beijo entre Isaura e Pedro nada tem de romanceado: é poético e sinestésico, e por isso, mais próximo da realidade. Essa pulsão sexual de Isaura marca o rompimento de sua crisálida, não somente para as relações amorosas, mas para a vida. Sem fechar os olhos ao que é próprio da adolescência, o conto se desenrola com a protagonista menina se descobrindo mulher.

O tema também está presente em "Eros de luto". Augusto, o protagonista, é descrito como um jovem que desde sempre queria morrer, e por isso, machucava-se. Como ninguém compreendia suas atitudes, era calado e solitário, e imaginava, na escuridão de seu quarto, que as estrelas eram suas amantes. Dava um nome e uma história para cada uma delas. Após ser flagrado por um vizinho, desistiu de seu harém por um tempo, quando

[...] chegou uma noite em que ele acordou suado, com uma excitação que amolecia umas partes do corpo e latejava no centro como a dor de um parto que não tem espaço para se expandir. Arrancou uns pelos da perna, tentou morder a palma da mão e acariciou o sexo com violência. Parecia estar esgarçando a pele espessa do prazer. E foi como uma lufada que o líquido grosso e leitoso espirrou do centro dele e foi escorrendo pelas coxas de Irene, pela nuca de Sofia até manchar o traje impecável de Leonor. Gozou na inocência de Lígia, se lambuzou no batom de Zulmira, beijou os pés de Nadja querendo demais fazer uma zorra no espaço sideral (MARINHO, 1989, p. 60).

Tópico ordinário para jovens, mas constrangedor para adultos, a masturbação é descrita através de imagens sutis e zombeteiras, apresentando ao leitor um protagonista com desejos sexuais a flor da pele e que tem seu momento de liberdade no escuro de seu quarto, sem frivolidades, fugindo dos estereótipos de jovens assexuados corriqueiros às narrativas nacionais. $\mathrm{O}$ crescimento emocional de Augusto acontecerá simultaneamente à vivência de sua primeira relação amorosa mais amadurecida, quando conhece Cecília, que acabara de fazer um aborto.

A qualidade estética e temática explica a presença desse texto no livro Amor em tom maior: contos latino-americanos, de 2004, que saiu pelo grupo Coedição Latino-americana, coordenado pelo 
Cerlalc e que tem apoio da Unesco. Como apontado no título, são quinze contos de escritores latinoamericanos, dos quais o único brasileiro é Marinho. Em comum, apresentam protagonistas jovens em suas venturas e desventuras amorosas.

Tendo em vista as temáticas abordadas, é louvável que já em seu início de carreira, Marinho tenha fugido de conservadorismos hipócritas e trate a sexualidade como parte da vida. Não é sem motivo que o livro recebeu o prêmio APCA - Associação Paulista de Críticos de Arte - de melhor livro juvenil e o selo de Altamente recomendável para jovens da FNLIJ.

\section{Um breve balanço}

Seu último livro publicado, na década que aqui se propôs abordar, é esclarecedor no sentido de confirmar que Marinho se inseriu no segmento em questão por uma editora marcadamente voltada à escola, mas nem por isso fez concessões que costumam agradar pais e educadores, ainda que não deixe de apresentar em seus textos, situações que visivelmente levam em consideração o leitor juvenil, como a linguagem esteticamente trabalhada, mas acessível. Em entrevista a FAAP, Marinho comentou a respeito de sua produção juvenil e o mercado:

Mas esse negócio de literatura indicada pra jovem, eu acho que é mais uma questão de perspectiva editorial mesmo. Porque o grande mercado hoje é a criança ou o jovem leitor. Então, eu escrevo um tipo de literatura... [pausa] eu recebo cartas permanentemente. Adulto lê muito. É indicado pra jovens, o jovem lê, mas o adulto também. Acredito que seja uma literatura que intermedeie esses universos, exatamente pela linguagem metafórica, mas eu acho que essa é mais uma questão de perspectiva editorial mesmo, de mercado (MARINHO, 1992).

Marinho mostra sua consciência sobre a rentabilidade do comércio de livros infantis e juvenis, mas não nega seus supostos destinatários em vista da possibilidade de que esse aspecto possa conspurcar sua produção. Ao contrário. Como foi possível acompanhar por esse breve panorama de sua obra na década de 1980, desde o início, sua produção para o público juvenilapresenta significativa originalidade ao revelar um diálogo produtivo entre a tradição literária e a sua sensibilidade criativa, mostrando que sua inserção no segmento se dá por meio de uma relação de respeito às potencialidades dessa literatura e de seus possíveis leitores. Perspectiva que se mantém e é aprimorada nas próximas décadas de sua produção. 


\section{Referências}

\section{Obras de Jorge Miguel Marinho}

MARINHO, Jorge Miguel. O talho. São Paulo: Loyola, 1981.

. Escarcéu dos corpos. São Paulo: Brasiliense, 1984.

. A menina que sonhava e sonhou. Ilustrações de Alcy. São Paulo: FTD, 1986.

. Dengos e carrancas de um pasto. Ilustrações de Helena Alexandrino. São Paulo: FTD, 1987.

. Um amor de maria-mole. Ilustrações de Rosa Schettino. Belo Horizonte: Lê, 1987.

. A visitação do amor: uma história mágica em dó maior. São Paulo: Contexto, 1987.

. Na curva das emoções: histórias de pequenas e grandes descobertas. Ilustrações de Afonso Maria Fonseca de

Oliveira. São Paulo: Melhoramentos, 1989.

Geral

CECCANTINI, João L. C. T. Uma estética da formação: vinte anos de Literatura Juvenil Brasileira premiada (19781997). 2000. 461 f. Tese (Doutorado em Literatura) - Faculdade de Ciências e Letras de Assis, Universidade Estadual Paulista, Assis, 2000.

LAJOLO, Marisa. Circulação e consumo do livro infantil brasileiro: um percurso marcado. In: KHÉDE, Sônia S. Literatura infanto-juvenil: um gênero polêmico. 2. ed. Porto Alegre: Mercado Aberto, 1986. p. 43-55.

; ZILBERMAN, Regina. Literatura infantil brasileira: história e histórias. 2. ed. São Paulo: Ática, 1985.

MACHADO, Ana M. Pelas frestas e brechas: importância da literatura infanto-juvenil brasileira. In: Balaio:

leituras e livros. Rio de Janeiro: Nova Fronteira, 2007. p. 112-131.

MARINHO, Jorge Miguel. Entrevista para a FAAP em 1992. $11 \mathrm{~min}$. Disponível em: <http://www.casadojorge.com. br/>. Acesso em: jan. 2016.

. Respostas a Jorge Vasconcelos (para o site da Ática). 1994. Disponível em: <http://www.casadojorge.com.br/ olho/textos/jorge.htm>. Acesso em: jan. 2016.

PELLEGRINI, Tânia. A imagem e a letra: aspectos da ficção brasileira contemporânea. Campinas/SP: Mercado de Letras; São Paulo: FAPESP, 1999. 